\title{
Phenylboronic acid catalysed synthesis of 1,5-benzodiazepines via cyclocondensation of $o$-phenylenediamine and ketones
}

\author{
SANTOSH V GOSWAMI, PRASHANT B THORAT and SUDHAKAR R BHUSARE* \\ Department of Chemistry, Dnyanopasak College, Parbhani 431 401, India \\ e-mail: bhusare71@yahoo.com
}

MS received 28 November 2012; revised 27 January 2013; accepted 1 March 2013

\begin{abstract}
Phenylboronic acid has been found to be an efficient catalyst for the synthesis of 1,5benzodiazepine derivatives via cyclocondensation of $o$-phenylenediamine and various ketones in good to excellent yields (82-91\%) using acetonitrile as solvent at reflux condition. The remarkable advantages offered by this method are easy mild reaction condition, experimental work up and good to excellent yields of products.
\end{abstract}

Keywords. Phenylboronic acid; o-phenylenediamine; ketones; 1,5-benzodiazepines.

\section{Introduction}

Benzodiazepine is significant class of biologically active compounds and gaining great consideration in the field of medicinal and pharmaceutical chemistry due to their application as anticonvulsant, antiinflammatory, analgesic, sedative agents and hypnotic activity. ${ }^{1-5}$ The 1,5-benzodiazepine derivatives are also employed as dyes for acrylic fibers in photography. ${ }^{6}$ Moreover benzodiazepines are effective precursors for the synthesis of other fused ring compounds such as triazolo, oxadiazolo, oxazino or furano-benzodiazepines. ${ }^{7-10}$ In general, cyclocondensation of $o$-phenylenediamines with carbonyl compounds is one of the conventional synthetic methods for the synthesis of 1,5-benzodiazepine derivatives. ${ }^{11}$

A variety of catalysts, such as $\mathrm{CeCl}_{3}-\mathrm{NaI} / \mathrm{SiO}_{2},{ }^{12}$ $\mathrm{SmI}_{2},{ }^{13} \mathrm{YbCl}_{3},{ }^{14} \mathrm{MgO} / \mathrm{POCl}_{3},{ }^{15}$ zeolites, ${ }^{16} \mathrm{Ga}(\mathrm{OTf})_{3},{ }^{17}$ Amberlyst-21- $\mathrm{Yb}(\mathrm{OPf})_{3},{ }^{18} \mathrm{Ag}_{3} \mathrm{PW}_{12} \mathrm{O}_{40},{ }^{19}$ boric acid, ${ }^{20}$ fluorous aqueous emulsion ${ }^{21} \mathrm{FeAlP}-550,{ }^{22}$ iodine, ${ }^{23}$ Ytterbium perfluorooctanesulphonate $\left[\mathrm{Yb}(\mathrm{OPf})_{3}\right],{ }^{24}$ 2,4,6-Trichloro-1,3,5-triazine ${ }^{25}$ and multicite solid catalyst ${ }^{26}$ have been utilized for this synthesis. However, these protocols are related with some disadvantages like hazardous reaction condition, extended reaction time and also use of harmful catalyst and organic solvent. Since, 1,5-benzodiazepines having great significance in pharmaceutical and medicinal fields. Thus, there is still necessity to develop an efficient protocol for the

*For correspondence synthesis of 1,5-benzodiazepines. Recently boronic acids have been employed as an efficient Lewis acid catalyst in synthetic organic chemistry. ${ }^{27-34}$ Herein we describe the use of phenylboronic acid as Lewis acid catalyst for the synthesis of 1,5-benzodiazepine derivatives. This transformation was performed by condensation reaction of $o$-phenylenediamine and ketones in the presence of catalytic amount of phenylboronic acid in acetonitrile solvent under reflux condition (scheme 1).

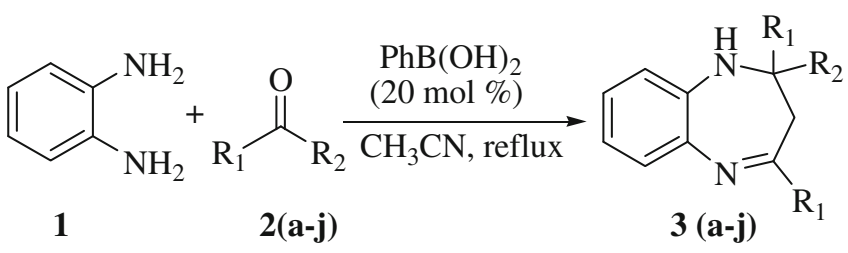

Scheme 1. Synthesis of 1,5-benzodiazepines via condensation of $o$-phenylenediamine with ketone.

\section{Experimental}

All solvents were used as commercial anhydrous grade without further purification. Aluminium sheets $20 \times$ $20 \mathrm{~cm}$, Silica gel $60 \mathrm{~F}_{254}$, Merck grade was used for thinlayer chromatography (TLC) to determine progress of reaction. Column chromatography was carried out over silica gel (80-120 mesh). Melting points were determined in open capillary tube and are uncorrected. ${ }^{1} \mathrm{H}$ NMR spectra were recorded on a Bruker-300 $\mathrm{MHz}$ spectrometer using $\mathrm{CDCl}_{3}$ as solvent and tetramethylsilane (TMS) as an internal standard. ${ }^{13} \mathrm{C}$ NMR 
spectra were recorded on a Bruker- $300 \mathrm{MHz}$ spectrometer using $\mathrm{CDCl}_{3}$ as solvent. Mass spectra were taken on Polaris-Q Thermo-scientific GC-MS.

\subsection{General procedure for the synthesis of derivatives $(3 a-j)$}

A mixture of $o$-phenylenediamine $(1 \mathrm{mmol})$, ketones ( $2.5 \mathrm{mmol})$ and phenylboronic acid $(20 \mathrm{~mol} \%)$ in acetonitrile solvent $(15 \mathrm{~mL})$ was refluxed for the appropriate (see table 2). After completion of reaction indicated by TLC (pet ether: ethyl acetate $8: 2$ ), the reaction mixture was diluted with $10 \mathrm{~mL}$ water and extracted with ethyl acetate $(2 \times 20 \mathrm{~mL})$. The combined organic layers were dried over anhydrous $\mathrm{Na}_{2} \mathrm{SO}_{4}$ and the solvent was evaporated under reduced pressure. The obtained product was purified by column chromatography using silica gel mesh 80-120 to afford the pure product.

\subsection{Characterization}

2.2a 2,3-Dihydro-2,2,4-trimethyl-1H-benzo-[1,4]diazepine (3a): Yellow solid; ${ }^{1} \mathrm{H}$ NMR $\left(300 \mathrm{MHz}, \mathrm{CDCl}_{3}\right): \delta$ 1.62 (s, 6H), 2.46 (s, 2H), 2.68 (s, 3H), 3.10 (br s, 1H,
$\mathrm{NH}), 6.72-7.10(\mathrm{~m}, 4 \mathrm{H}) ;{ }^{13} \mathrm{C} \mathrm{NMR}\left(300 \mathrm{MHz}, \mathrm{CDCl}_{3}\right)$ : $\delta$ 30.8, 33.5, 43.6, 66.4, 118.4, 122.6, 127.2, 128.8, 135.7, 142.1, 170.3; GC-MS, m/z: 188 (M+).; Elemental Analysis: Anal. Calcd for $\mathrm{C}_{12} \mathrm{H}_{16} \mathrm{~N}_{2}$ : C, 76.55; H, 8.57; N, 14.88; Found C, 76.52; H, 8.59; N, 14.84.

$2.2 \mathrm{~b}$ 2,3-dihydro-2-methyl-2,4-diphenyl-1H-benzo-[1, 4]diazepine (3c): Yellow solid; ${ }^{1} \mathrm{H}$ NMR $(300 \mathrm{MHz}$, $\left.\mathrm{CDCl}_{3}\right): \delta 1.82(\mathrm{~s}, 3 \mathrm{H}), 3.14(\mathrm{~s}, 2 \mathrm{H}), 3.60(\mathrm{br} \mathrm{s}, 1 \mathrm{H}$, $\mathrm{NH})$, 6.72-7.14 (m, 2H), 7.30-7.49 (m, 10H), 7.64$7.74(\mathrm{~m}, 2 \mathrm{H}) ;{ }^{13} \mathrm{C}$ NMR $\left(300 \mathrm{MHz}, \mathrm{CDCl}_{3}\right): \delta 32.3$, $44.2,72.5,122.5,123.8,125.9,127.8,128.2,128.9$, 130.0, 130.6, 131.2, 132.5, 137.5, 139.8, 142.1, 147.2, 168.3; GC-MS, m/z: $312(\mathrm{M}+)$; Elemental Analysis: Anal. Calcd for $\mathrm{C}_{22} \mathrm{H}_{20} \mathrm{~N}_{2}$ : C, 84.58; H, 6.45; N, 8.97; Found C, 84.55; H, 6.47; N, 8.94.

2.2c 10-Spirocyclohexan-2,3,4,10,11,11a-hexahydro1H-dibenzo[1,4]diazepine (3j): Yellow solid; ${ }^{1} \mathrm{H}$ NMR $\left(300 \mathrm{MHz}, \mathrm{CDCl}_{3}\right): \delta 1.02-2.49(\mathrm{~m}, 17 \mathrm{H})$, 3.15(m, 2H), 3.54 (br s, 1H, NH), 6.89-7.42 (m, 4H); ${ }^{13} \mathrm{C}$ NMR $\left(300 \mathrm{MHz}, \mathrm{CDCl}_{3}\right): \delta 22.3,22.8,23.9,24.3$, $24.9,26.8,34.5,35.4,39.9,42.4,55.2,65.6,122.4$,

Table 1. Effect of solvent and catalytic loading on synthesis of 1,5-benzodiazepines under different condition. ${ }^{\mathrm{a}}$

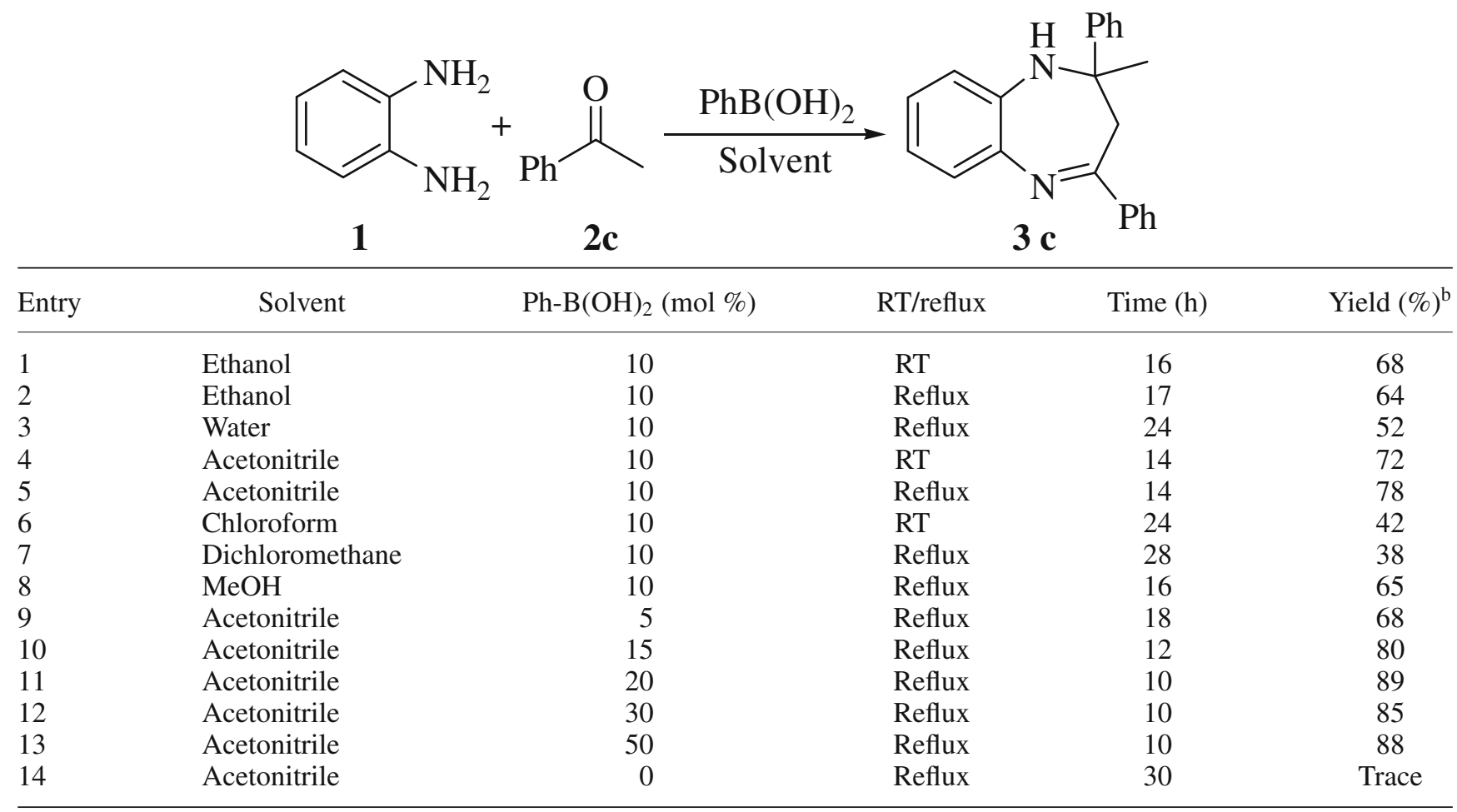

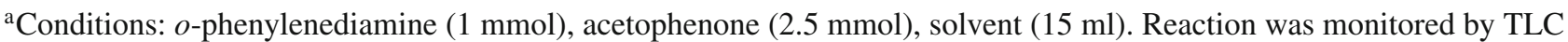
${ }^{\mathrm{b}}$ Isolated yield RT: Room temperature 
127.5, 130.5, 139.7, 144.3, 176.4; GC-MS, $m / z: 268$

$(\mathrm{M}+)$; Elemental Analysis: Anal. Calcd for $\mathrm{C}_{18} \mathrm{H}_{24} \mathrm{~N}_{2}$ :

C, 80.55; H, 9.01; N, 10.44; Found C, 80.53; H, 9.04;

N, 10.48 .

\section{Results and discussion}

In continuation of our interest in synthesis of heterocycles using boronic acids, ${ }^{35-37}$ herein we explain the

Table 2. Synthesis of 1,5-benzodiazepines catalysed by phenylboronic acid. ${ }^{\mathrm{a}}$

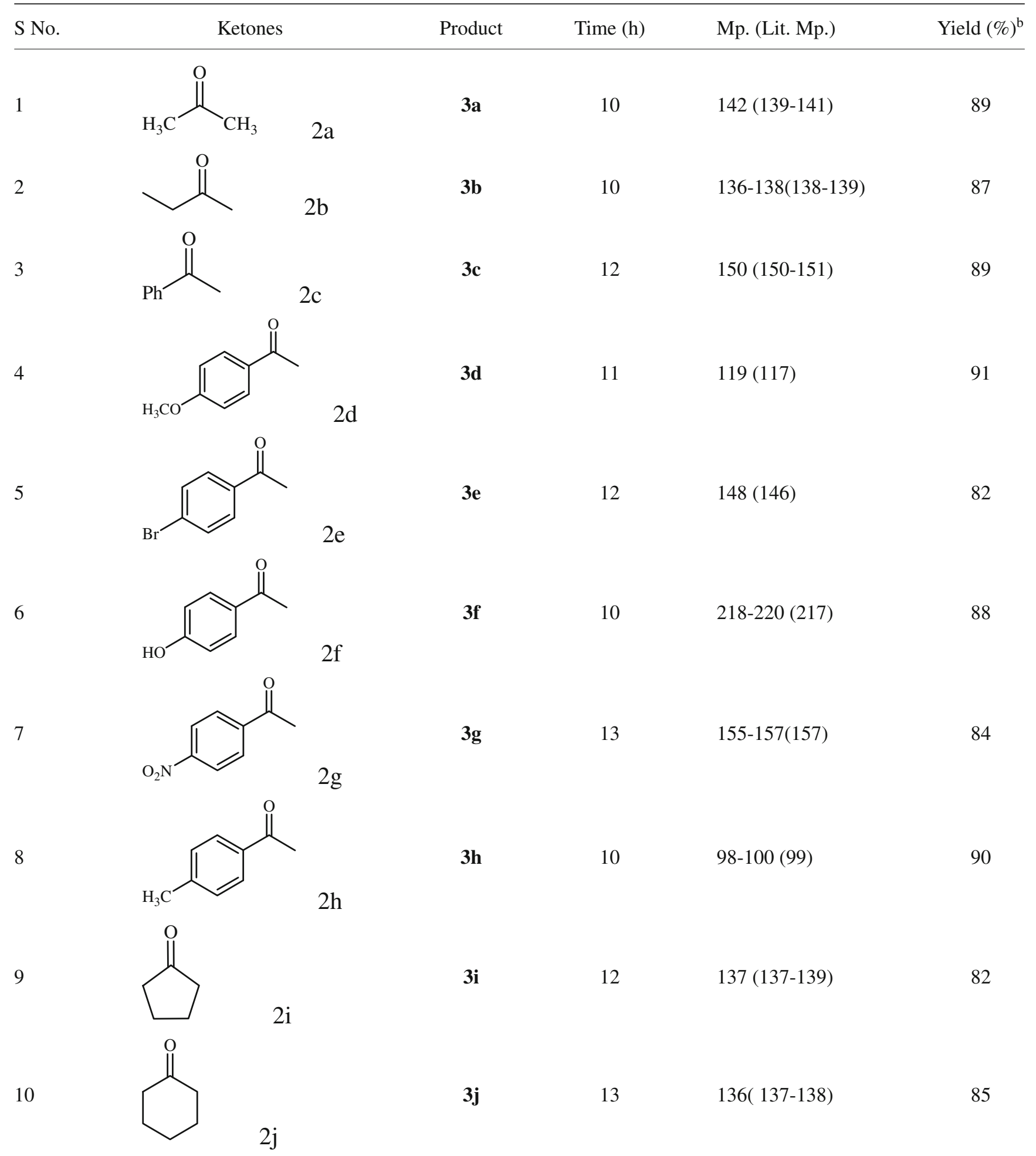

${ }^{a}$ Conditions: $o$-phenylenediamine $(1 \mathrm{mmol})$, ketone $(2.5 \mathrm{mmol})$, phenylboronic acid $(20 \mathrm{~mol} \%)$ acetonitrile $(15 \mathrm{~mL})$. Reaction was monitored by TLC

${ }^{\mathrm{b}}$ Isolated yield 
synthesis of 1,5-benzodiazepine derivatives. The synthesis of this heterocycles was accomplished by condensation reaction of $o$-phenylenediamine and ketones in the presence of catalytic amount of phenylboronic acid in acetonitrile solvent under reflux condition.

Initially we studied the effect of solvent and catalytic loading on the synthesis of 1,5-benzodiazepine derivatives under different condition using model reaction of $o$-phenylenediamine and acetophenone. In the initial stage, for the optimization of suitable condition a model reaction screened using different solvent at room temperature and reflux condition to check the effectiveness of phenylboronic acid $(10 \mathrm{~mol} \%)$. The results are summarized in table 1 (entry 1-12). In the solvent ethanol, reaction was completed within $16 \mathrm{~h}$ at room temperature and $17 \mathrm{~h}$ at reflux condition but the product yield was not meeting our expectations (table 1, entry 1 and 2, respectively). In the solvent water, $52 \%$ yield was observed at reflux condition after $24 \mathrm{~h}$. Satisfactorily yield $(78 \%)$ was observed when reaction was carried out in acetonitrile solvent at reflux condition (table 1 , entry 5). Moreover the reaction in solvents chloroform, dichloromethane needed more reaction time and gave low yield 42 and $38 \%$, respectively (table 1, entry 6 and 7, respectively) and in the solvent methanol 65\% yield of desired product was obtained after $16 \mathrm{~h}$. So we continued our investigation in the solvent acetonitrile at reflux condition.

Further, we examined the effect of catalytic loading on the model reaction to get the excellent yield of desired product 3c. At the catalytic loading $5 \mathrm{~mol} \%$ and $15 \mathrm{~mol} \%$, reaction afforded $68 \%$ and $80 \%$ yield, respectively (table 1, entry 9 and 10, respectively). The excellent result for the reaction was offered at the catalytic loading $20 \mathrm{~mol} \%$ of the catalyst phenylboronic acid. The reaction was completed within $10 \mathrm{~h}$ and offered the desired product 3a in excellent yield 89\% (table 1, entry 11). Further, increasing the catalytic loading up to $50 \mathrm{~mol} \%$ did not show any enhancement in the progress of reaction time and yield of desired product (table 1, entry 12 and 13).

To test the significance of phenylboronic acid as catalyst, reaction was carried out in the absence of catalyst. We noticed that, trace amount of yield was observed after $30 \mathrm{~h}$ (table 1, entry 14).

Under the optimized reaction conditions, different ketones were allowed to react with $o$-phenylenediamine. All the reactions proceeded efficiently with wide range of ketones affording good to excellent yield of the corresponding products (table 2). Cyclic ketones such as cyclopentanone and cyclohexanone also reacted effectively to produce the corresponding fused ring benzodiazepines (table 2, entry 9 and 10, respectively). The results are listed in (table 2).
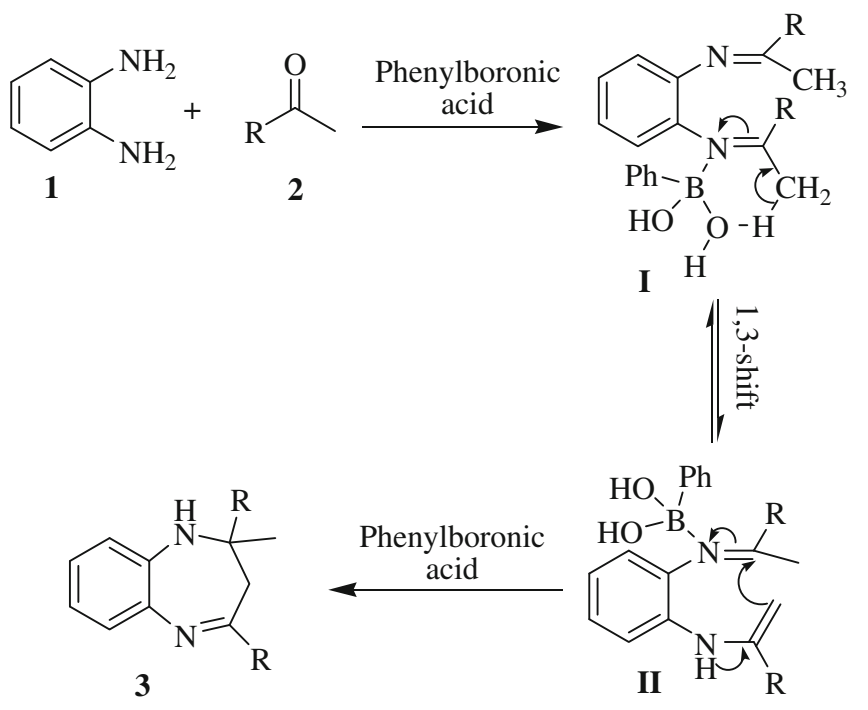

Figure 1. Plausible mechanism for synthesis of 1,5benzodiazepines.

A plausible mechanism for the formation of 1,5benzodiazepine is shown in figure 1. Amino groups of $o$-phenylenediamine attack carbonyl group of ketone in the presence of phenylboronic acid, giving the intermediate diimine I. Then, 1,3-shift of the hydrogen attached methyl group occurs to afford an intermediate enamine II, which cyclizes to produce desired product 1,5-benzodiazepine 3 .

\section{Conclusion}

In conclusion, we have presented simple and facile method for the synthesis of 1,5-benzodiazepine derivatives by cyclocondensation of $o$-phenylenediamine and ketones using phenylboronic acid as catalyst in acetonitrile solvent under reflux condition. This transformation was successfully studied for different range of ketones. The mild reaction condition, easy experimental operation and good to excellent yield with a wide range of ketones are some of the striking features of this protocol.

\section{Acknowledgements}

We thank Dr. P L More and Dr. W N Jadhav, Dnyanopasak College, Parbhani for providing necessary facilities and financial support for this work by DST-SERC, New Delhi (SR/FT/CS-023/2008) is highly appreciated.

\section{References}

1. de Baun J R, Pallos, F M and Baker D R 1977 Chem. Abstracts $\mathbf{8 6} 5498$ 
2. Schultz H 1982 Benzodiazepines (Heidelberg: Springer)

3. Smiley R K 1979 Comprehensive organic chemistry (Oxford: Pergamon)

4. Landquist J K 1984 Comprehensive heterocyclic chemistry, vol. 1 (Oxford: Pergamon)

5. Randall L O, Kappel B Garattini S and Mussini E 1973 Pharmacological activity of some benzodiazepines and their metabolites, in Benzodiazepines, (eds) (New York: Raven)

6. Haris R C and Straley J M 1968 US Patent 1, 537, 757

7. El-Sayed A M, Abdel-Ghany H and El-Saghier A M M 1999 Synth. Commun. 293561

8. Xu J X, Wu H T and Jin S 1999 Chin. J. Chem. 1784

9. Zhang X Y, Xu J X and Jin S 1999 Chin. J. Chem. 17 404

10. Kim K, Volkman S K and Ellman J A 1998 J. Braz. Chem. Soc. 9375

11. Ried W and Torinus E 1959 Chem. Ber. 922902

12. Sabitha G, Reddy G S, Reddy K B, Reddy N M and Yadav J S 2004 Adv. Synth. Catal. 346921

13. Luo Y Q, Xu F, Han X Y and Shen Q 2005 Chin. J. Chem. 231417

14. Wu J T, Xu F, Zhou Z Q and Shen Q 2006 Synth. Commun. 36457

15. Balakrishna M S and Kaboundin B 2001 Tetrahedron Lett. 421127

16. Tajbakhsh M, Heravi M M, Mohajerani B and Ahmadia A N 2006 J. Mol. Catal. A: Chem. 247213

17. Pan X Q, Zou J P, Huang Z H and Zhang W 2008 Tetrahedron Lett. 495302

18. Tao F and Yi W B 2008 Lett. Org. Chem. 5655

19. Yadav J S, Reddy B V S, Praveenkumar S, Nagaiah K, Lingaiah N and Saiprasad P S 2004 Synthesis 6 901
20. Zhou X, Zhang M Y, Gao S T, Ma J J, Wang C and Liu C 2009 Chin. Chem. Lett. 20905

21. Yi W B and Cai C 2009 J. Fluorine Chem. 1301054

22. Vijayasankar A V, Deepa S, Venugopal B R and Nagaraju N 2010 Chin. J. Catal. 311321

23. Bandgar B P, Bettigeri S V and Joshi N S 2004 Synth. Commun. 341447

24. Yi W and Cai C 2007 Synth. Commun. 373827

25. Kuo C W, Wang C C, Kavala V and Yao C F 2008 Molecules 132313

26. Climent M J, Corma A, Iborra S and Santos L L 2009 Chem. A Eur. J. 158834

27. Zheng H and Hall D G 2010 Tetrahedron Lett. 51 3561

28. Frutos R P, Tampone T, Mulder J A, Xu Y, Reeves D, Wang X-J, Zhang L, Krishnamurthy D and Senanayake C H 2011 Tetrahedron Lett. 522465

29. Tale R H and Adude R N 2006 Tetrahedron Lett. 477263

30. McCubbin J A, Hosseini H and Krokhin O V 2010 J. Org. Chem. 75959

31. Sridhar R and Perumal P T 2005 Tetrahedron 612465

32. Debache A, Boumoud B, Amimour M, Belfaitah A, Rhouatia S and Carbonib B 2006 Tetrahedron Lett. 47 5697

33. Lopez-Ruiz H, Briseno-Ortega H, Rojas-Lima S, Santillan R and Farfan N 2011 Tetrahedron Lett. 524308

34. Tibhe G D, Bedolla-Medrano M, Cativiela C and Ordonez M 2012 Synlett 231931

35. Goswami S V, Thorat P B and Bhusare S R 2012 Tetrahedron Lett. 536771

36. Goswami S V, Thorat P B and Bhusare S R 2012 Heterocycl. Commun. 18245

37. Adude R N, Tigote R M, Goswami S V and Bhusare S R 2012 Int. J. Ind. Chem. 36 